\title{
Colloid carcinoma not associated with intraductal papillary mucinous neoplasm: special variant of pancreatic ductal adenocarcinoma
}

\author{
Pritik A Shah (D) , 1,2 Veena Ramaswamy, ${ }^{3}$ Subash Kallukatte Gopala, ${ }^{1}$ \\ Raghavendra Babu ${ }^{1}$
}

${ }^{1}$ Department of

Hepatopancreatobiliary (HPB) Surgery and Liver Transplant, Healthcare Global Enterprises, Bangalore, Karnataka, India ${ }^{2}$ Department of Surgery, Bangalore Medical College and Research Institute, Bangalore, Karnataka, India

${ }^{3}$ Department of Pathology, Strand Life Sciences, Bangalore, Karnataka, India

Correspondence to Dr Raghavendra Babu; raghavendrababuj@gmail.com

Accepted 14 January 2022

\section{DESCRIPTION}

A female patient in her 70s presented with yellow discolouration of her skin for the past 15 days. The patient was investigated further with the following laboratory findings: the patient had elevated levels of bilirubin $(3.5 \mathrm{mg} / \mathrm{dL})$, alanine transaminase $(160 \mathrm{IU} / \mathrm{L})$, asparagine transaminase $(177 \mathrm{IU} / \mathrm{L})$, alkaline phosphatase $(1361 \mathrm{IU} / \mathrm{L})$ and serum marker: CA19-9 (9300 U/mL). Serum sodium levels were low $(123 \mathrm{mEq} / \mathrm{L})$. A positron emission tomography-CT (figure 1) revealed heterogeneously enhancing mass involving the pancreatic duct, measuring approximately $5.6 \times 3.8 \times 6$ $\mathrm{cm}$. There was adjacent peripancreatic infiltration/ fat stranding with the tumour being close but not involving the superior mesenteric artery and superior mesenteric vein. There was an infiltration of the adjacent second part of the duodenum with diffuse pancreatic parenchymal atrophy and fatty replacement. The main pancreatic duct appeared dilated with calculi, the largest of which measured $1.8 \times 0.6 \mathrm{~cm}$ in dimension. Few enlarged/prominent suprapancreatic, periportal, portacaval and retrocaval lymph nodes are noted, the largest one measuring $1.7 \times 1.1 \mathrm{~cm}$. Mild to moderate intrahepatic and extrahepatic biliary dilatation was also noticed.

After obtaining informed consent, a Whipple procedure or pancreaticoduodenectomy was undertaken. Intraoperative findings showed a mass $7 \times 7 \mathrm{~cm}$ in dimension involved in the head of the pancreas and uncinate process. No surrounding evidence of any distant metastasis was observed

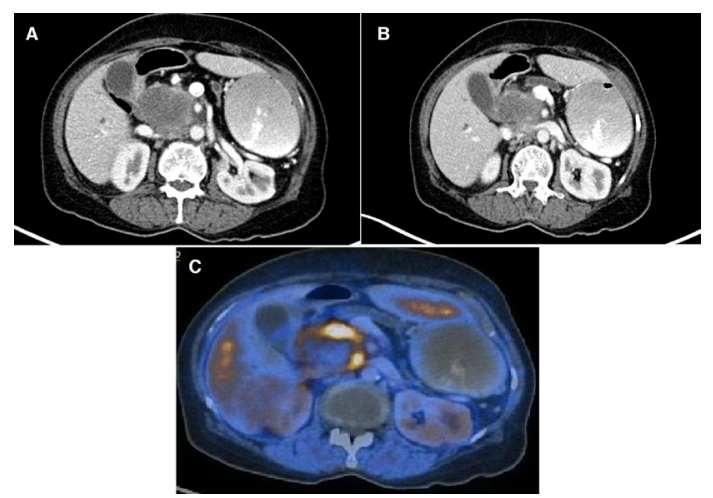

Figure $1 \mathrm{CT}$ scan image showing the pancreatic tumour mass $(A, B)$. Positron emission tomography scan image showing the pancreatic tumour mass (C).

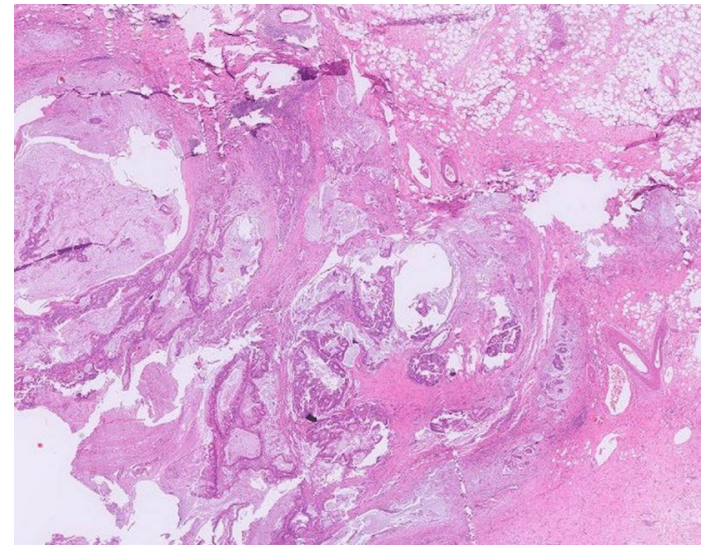

Figure 2 Histopathology image (H\&E stained): lakes of mucoid areas (low magnification: pT3NOMO).

in the liver or peritoneum. The tumour was in close approximation to the superior mesenteric artery and superior mesenteric vein. An artery-first approach was used to dissect the uncinate process and the tumour then could be separated from the vein without any resection. On further exploration, the pancreas was entirely replaced by fat with calculi inside the pancreatic duct.

Tumour histological type was a variation of ductal adenocarcinoma: colloid carcinoma (mucinous non-cystic carcinoma) and tumour histological grade were that of a well-differentiated type. On macroscopic evaluation, the tumour, which was at the head of the pancreas, appeared to be partially solid, lobulated and partly cystic. Microscopic

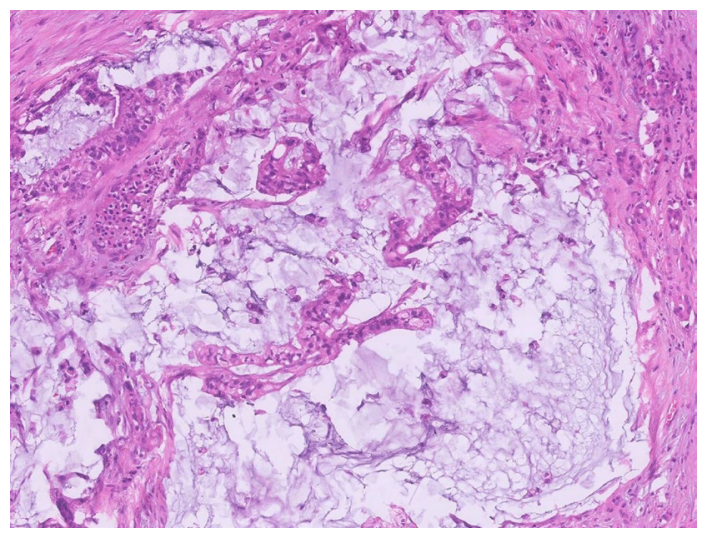

Figure 3 Histopathology image (H\&E stained): lakes of mucoid areas (high magnification: pT3NOM0). 
evaluation revealed lakes of mucoid areas as shown in figures 2 and 3. A diagnosis of colloid carcinoma of the pancreas with free margins and 0/54 lymph nodes showing metastasis was made. The pathological stage (Eighth American Joint Committee on Cancer tumour-node-metastasis staging of pancreatic cancer staging system) was defined as pT3N0M0 for this tumour. No evidence of intraductal papillary mucinous neoplasm findings was seen.

Currently, guidelines to treat colloid carcinoma are not specific and clearly elucidated. The mainstay considered is still surgery, especially if encasement of vessels or surrounding structures is absent and there is no evidence of metastasis. ${ }^{1-3}$ Whipple procedure, pylorus-preserving pancreatoduodenectomy, distal pancreatectomy or a subtotal pancreatectomy can be considered as surgeries for colloid carcinoma management. ${ }^{4}$ The location, size and extent of the involvement would help determine the type of procedure to be performed. However, it has been observed that chemotherapy, radiation therapy or other modalities of

\section{Learning points}

Colloid carcinoma of the pancreas is a rare subtype of pancreatic cancer. Intraductal papillary mucinous neoplasms (IPMNs), when invasive, are separated into either colloid carcinoma or tubular carcinoma.

- The pathology of this case showed colloid carcinoma without evidence of IPMN, which is a deviation from the normal association and expectation. The second rarity of associated findings was that of colloid carcinoma with calcifications.

- Currently, guidelines to treat colloid carcinoma are not specific and elucidated. The mainstay considered is still surgery, especially if encasement of vessels or surrounding structures is absent and there is no evidence of metastasis. such have not shown promising postoperative survival rates. In comparison with pancreatic ductal adenocarcinoma (PDAC), the prognostic 5-year survival rate was found to be $>55 \%$ as compared with $10 \%$ in PDAC. There also exists evidence that certain individuals with metastasis to lymph nodes from colloid carcinoma have had a good 10 -year survival rate. ${ }^{23}$

\section{Twitter Pritik A Shah @Pritik201}

Contributors PAS drafted the original manuscript and obtained all the data for the same. RB and SKG supervised the aspects from a surgical oncologist's point, reviewed the manuscript and edited it for intellectual content. VR supervised the aspects from a histopathologist's point of view and revised the manuscript for intellectual pathology content. All authors approved of the final submission and have made substantial contributions to the manuscript.

Funding The authors have not declared a specific grant for this research from any funding agency in the public, commercial or not-for-profit sectors.

Competing interests None declared.

Patient consent for publication Obtained.

Provenance and peer review Not commissioned; externally peer reviewed.

Case reports provide a valuable learning resource for the scientific community and can indicate areas of interest for future research. They should not be used in isolation to guide treatment choices or public health policy.

\section{ORCID iD}

Pritik A Shah http://orcid.org/0000-0002-4175-9043

\section{REFERENCES}

1 Waters JA, Schnelldorfer T, Aguilar-Saavedra JR, et al. Survival after resection for invasive intraductal papillary mucinous neoplasm and for pancreatic adenocarcinoma: a multi-institutional comparison according to American joint Committee on cancer stage. J Am Coll Surg 2011;213:275-83.

2 Plerhoples TA, Ahdoot M, DiMaio MA, et al. Colloid carcinoma of the pancreas. Dig Dis Sci 2011;56:1295-8.

3 Kalaitzakis E, Braden B, Trivedi P, et al. Intraductal papillary mucinous neoplasm in chronic calcifying pancreatitis: egg or hen? World J Gastroenterol 2009;15:1273-5.

4 Gao Y, Zhu Y-Y, Yuan Z. Colloid (mucinous non-cystic) carcinoma of the pancreas: a case report. Oncol Lett 2015;10:3195-8.

Copyright 2022 BMJ Publishing Group. All rights reserved. For permission to reuse any of this content visit

https://www.bmj.com/company/products-services/rights-and-licensing/permissions/

BMJ Case Report Fellows may re-use this article for personal use and teaching without any further permission.

Become a Fellow of BMJ Case Reports today and you can:

- Submit as many cases as you like

- Enjoy fast sympathetic peer review and rapid publication of accepted articles

- Access all the published articles

- Re-use any of the published material for personal use and teaching without further permission

Customer Service

If you have any further queries about your subscription, please contact our customer services team on +44 (0) 2071111105 or via email at support@bmj.com.

Visit casereports.bmj.com for more articles like this and to become a Fellow 